\title{
EDITORIAL
}

\section{Special issue: gated communities}

URBAN DESIGN International (2008) 13, 211-212. doi:10.1057/udi.2008.32

Gated communities of various types and sizes have grown significantly in the past one to two decades. In line with this, the number of studies and publications has also steadily increased. Some of the contributions have been the result of an international group of scientists who have been tracking the global emergence and spread of gated communities, private neighbourhood governance and urban territorial enclosure since 1999. Its findings have so far been published in a series of books and special issues of journals (including Environment and Planning B 2002, Geographica Helvetica 2003, Ciudades 2003, Housing Studies 2005, Trialog 2006, Geojournal 2006, European Journal of Geography 2007, Housing Policy Debate 2007) and discussed in eight conferences (Hamburg 1999, Mainz 2001, New York 2003, New Orleans 2003, Glasgow 2004, Pretoria 2005, Paris 2007, and Chile 2009).

Despite the growing body of knowledge regarding gated communities and their implications for cities, there has been a limited focus on the spatial dimension of this phenomenon. There have been a number of geographical papers investigating the spatial impact of gated communities on a metropolitan or regional scale, whereas a limited number of authors have investigated the implications for city planning, including the seminal work by Blakely and Snyder, Fortress America (1997). However, despite the fact that some of the most distinguishing features of gated communities are their physical elements, including walls or electrified fences, ostentatious entrance gates and booms, and a range of other security measures such as CCTV cameras and alarm systems, very limited research has been conducted from an urban design/architectural perspective, or at a neighbourhood scale with a spatial focus.

Addressing the gap, this special issue of URBAN DESIGN International focuses on gated communities from a spatial perspective and more specifically at the level of urban design and architecture. The issue therefore investigates the phenomenon from the point of view of the urban form and the physical elements used to redefine and thus transform urban space - both physical and social space. As such, this collection of five papers is concerned with the nature and transformation of the built form through the proliferation of gated communities in contemporary urban environments.
Miao $\mathrm{Xu}$ and Zhen Yang's paper sets the scene with a theoretical discussion on the genesis and controversies around gated communities from an urban design perspective. They particularly raise concerns about the well-being of public space - one of the major concerns of urban design research. They argue that given the current political and socio-economic impetus behind the sense of fear, it is likely that the market demand for gated communities would continue to grow and become even stronger in the light of the growth of Neo-liberalism. Given this, they introduce three key elements at a design and policy level to minimise some of the negative impact of gated communities through physical intervention, namely fine-grained land subdivision, a reconsideration of the nature of the physical boundaries and the extensive provision of quality public spaces. They conclude that only liveable urban spaces can fill the socio-spatial gaps left between gated communities and their local urban neighbourhoods and therefore that proactive urban design is necessary to secure such spaces. Contextspecific research is, however, required to examine the feasibility of this type of design worldwide.

Finding alternative ways to approach urban design interventions to address security and other lifestyle concerns is also the theme of the next paper. Karina Landman investigates the relevance of gated communities as a specific urban design approach in a very particular context - South Africa. An analysis of these developments and the way certain ideas have been practically applied reveal their impact and implications, raising many questions around the appropriateness of international urban design approaches in postapartheid South Africa. She concludes that there is a need for a new form of urbanism that will consider the city as a whole system, made up out of smaller subsystems (eg neighbourhoods) that overlap and continuously interlink to produce a dynamic balance. Such a systemic approach could guide attempts to start exploring the principles and design implications of a more integrative eco-urbanism relevant to the challenges of the twenty-first century city.

Diana Sheinbaum also raises the importance of looking at the local context and re-interpreting urban spatial interventions from an historical understanding. She investigates gated communities in Mexico City from a 
historical perspective and explores the historical forms of urban space production and its relationship to different physical expressions of segregation. She concludes that self-segregation in the city has deep historical roots and that contemporary gated communities simply perpetuate an ongoing historical process of segregation that has characterised the socio-spatial structure of Mexico City for a very long time, rather than being an expression of new patterns of urban segregation. In this way, historical patterns can also repeat itself through built form.

Jill Grant and Leah Carson expand this theme of urban fragmentation, but from a smaller scale. They explore the spatial patterns that private streets generate in a specific region in Canada, Nova Scotia. This includes a description of the design features related to private streets and the socio-spatial implications that private streets generate. The analysis reveals different 'classes' of private landscapes. As many of the authors before, they express concerns with the privatisation of streets and urban spaces. Interestingly, they distinguish between the impacts of private streets in urban and rural areas. They conclude that while private streets in the urban context facilitate sustainability goals such as intensification and walkability, in the rural and exurban context private streets may contribute to a 'second-class landscape' where the affluent have good streets, the poor have potholes and everyone has to use their vehicles to go somewhere.

The final paper in this edition extends the debate to redefine our understanding of gated communities and urban segregation. Nadia Alaily-Mattar presents a thought provoking study on Beirut where the ensemble of static and dynamic segregation produces a new kind of segregation that seeps through the totality of the city rather than being restricted to certain localities. She maintains that this can be read as 'a layer superimposed on the city'. In this way, the paper discusses a new type of spatiality emerging in the city of Beirut in which a certain profile of citizens described as 'affluent status seeking individuals' practice different degrees of spatial segregation beyond the residential level. This gives rise to the production of a 'living space' composed of geographically and locally detached spaces that are connected to each other. The paper therefore highlights the creation of different types of boundaries, or that of a 'membrane' that isolates social entities and provides them with a sanctuary. She concludes that the apparent logic of this layer is detachment, which occurs across the city but in spatially defined localities. As such, she concludes, the process might refer more to aggregation than segregation.

Collectively, these papers illustrate the [re]emergence of specific types of physical elements to redefine secure and specific lifestyle space in contemporary cities across the world. This can happen through the re-use of old historical patterns and elements (eg Mexico City), the recollection of old ideas merged with contemporary trends (eg South Africa) and a complete reconceptualisation of detached spaces distributed across the city for use by a selective group of residents (eg Beirut). In this way, the effects of cross-fertilisation of design ideas and spatial patterns can span across time and place. This does not, however, only refer to cross-fertilisation between countries, but also within countries between different settlement types, as was the case in Canada. Although the privatisation of streets was found to have a positive impact on urban areas, its implications for rural and exurban areas seem to be more doubtful and less conducive in creating sustainable environments. This often relates to a lack of strong guidance from municipalities in terms of regulation or service delivery.

What emerged strongly from all of the papers were questions about the impact of various types of gated communities (differing in size and form) on the wellbeing and the use of public space. If one is to accept the proposition presented in the first paper that due to a growing market demand, gated communities is likely to remain and grow as a significant urban phenomenon of the twenty-first century city, then it indeed raises issues about the role of physical elements in determining the quality of public space and lives of residents making use of these spaces. This urges urban designers and architects to reconsider the way in which they conceptualise secure and lifestyle neighbourhoods and ask whether there are alternative ways to conceptualise the design of intermediate and transitional spaces to allow for greater integration and connection between gated communities and the public spaces in between. The aim would be to counter spatial segregation and social exclusion. It also points to the importance of understanding gated communities and various types of boundaries, not only at a city scale and from a socioeconomic perspective, but also from an urban design perspective or at a neighbourhood scale with a spatial focus. 